Cad.Est.Ling., Campinas, (38):109-120, Jan./Jun. 2000

\title{
SINGULARIDADE DISCURSIVA NA ENUNCIAÇÃO EM SEGUNDAS LINGUAS
}

\author{
SILVANA SERRANI INFANTE ${ }^{1}$ \\ (UNICAMP-DLA)
}

\section{INTRODUÇÃO}

A enunciação em segundas línguas nos põe diante de paradoxos e situações aparentemente inexplicáveis. Como é que pessoas comprovadamente muito inteligentes, que dizem querer muito falar uma determinada língua estrangeira/segunda língua (L2), fazem inumeráveis cursos, conhecem múltiplas regras gramaticais e um léxico considerável, muitas vezes, não conseguem se expressar significativamente na língua alvo? Na verdade, discriminar funções, como advertir, pedir, aconselhar, cobrar, agradecer, propor, etc. para uma mesma construção (por exemplo, uma estrutura condicional), ainda que sendo esclarecedor parece não bastar, e acontece que pessoas, mesmo conhecendo essas funções, ficam caladas ou muito confusas quando solicitadas a produzir e compreender em L2. O que é "aquilo" que faz com que às vezes "de repente" alguém comece a se expressar melhor na L2? Somente o melhor conhecimento de léxico e construções gramaticais? Qual o papel da subjetividade nisso? Perguntas como essas nos levaram a elaborar a proposta AREDA de estudo do processo de enunciação em segunda(s) língua(s) ${ }^{2}$.

Assim, um duplo propósito dá origem a este texto. Por um lado, focalizar a concepção do singular implementada na referida proposta, cuja base conceitual é a Semântica Discursiva da Análise do Discurso. Por outro lado, a finalidade deste trabalho é, também, salientar a relevância, para o domínio específico dos estudos da linguagem, do exame de antecedentes históricos e filiações teóricas das investigações, focalizando, sobretudo, a construção discursiva de paradigmas conceituais.

${ }^{1}$ Meu agradecimento especial aos colegas Walter C. Costa, da UFSC, e Lourenço Chacon, da UNESP, pelas cuidadosas leituras críticas da versão preliminar deste trabalho. Agradeço a Carlos R. Luis, da Univ. de Buenos Aires, a generosa indicação dos artigos de Aarsleff e Lakoff e suas consideraçöes durante a conversa que tivemos sobre o tema, na UBA, em julho de 1999. Sou muito grata a Manoel Corrêa, da USP, e a Pat Odber, da Univ. de Birmingham, pela contribuição para o achado de referências bibliográficas. Meu reconhecimento ao CNPq pelo apoio dado à pesquisa.

2 A proposta AREDA (Análise de Ressonâncias Discursivas em Depoimentos Abertos) consiste em realizar estudos de caso, visando a analisar, em depoimentos de enunciadores com experiência bi/multilíngie o funcionamento de ressonâncias discursivas na construção de suas representaçōes das línguas e culturas em cada caso e a relação com os modos de produção-compreensão lingüístico-discursiva em segunda(s) língua(s). A noção de ressonância de significação corresponde a uma interpretação discursiva da noção sintática de paráfrase. Uma explicação detalhada das categorias de análise utilizadas e dos procedimentos da proposta AREDA encontra-se nos trabalhos que publiquei em 1998 (ver Referências Bibliográficas). 
Esse exame requer um destaque particular no campo aplicado dos estudos da linguagem. Não é infreqüente que urgências de resultados pragmáticos funcionem como argumento (explícito ou implícito) para evitar o aprofundamento da filiação das concepções teórico-metodológicas implementadas. Assim, às vezes, podem ser propiciados tratamentos espontaneístas, ecléticos ou mesmo banalizadores dos processos em estudo. A reflexão sobre as filiações históricas contribui para situar melhor as pesquisas, bem como para distinguir a produção de conhecimentos efetivos do mero seguimento de modas ou tendências passageiras. Ilustrarei minha argumentação com leituras contemporâneas da Gramática Geral e Razoada de PortRoyal (GGR). Focalizarei a concepção e modos de análise das construções relativas, exemplificando com análises dessa marca, feitas em estudos da proposta AREDA e em abordagens formalistas-cognitivistas atuais, que afirmam tomar a GGR como referência teórica.

Para finalizar estas palavras introdutórias, gostaria de lembrar que a reflexão sobre o singular é crucial ao se repensar questões dos estudos teóricos da linguagem, das práticas pedagógicas e das políticas linguísticas. Tomar como referência momentos do debate sobre o universal e o particular é especialmente pertinente, no contexto atual em que a questão do 'universal' (na forma de língua: o inglês?, de meios: a Internet?, de políticas: a globalização?) parece querer se impor com renovada força. E o singular do sujeito contraditório e desejante nesse contexto? E o plurilingüismo? As perguntas estão formuladas. Procurarei, a seguir, expor caminhos de resposta.

\section{SINGULAR E CONTRADIÇÃO NO ESTUDO DA ENUNCIAÇÃO EM LÍNGUA ESTRANGEIRA: A PROPOSTA AREDA}

A partir de dois focos de estudo, a Semântica Discursiva, proposta pela Análise do Discurso ${ }^{3}$, e a Aquisição de Línguas, elaborei a proposta AREDA de investigação do processo de enunciação em segunda língua/língua estrangeira (L2). Nela, o estudo do particular ${ }^{4}$ e da singularidade enunciativa são focalizados, para apreender fatores de natureza não cognitiva que incidem no processo de enunciar em L2 $2^{5}$. Os depoimentos são obtidos mediante a gravação de respostas a perguntas abertas, nas quais o fundamental é a construção discursiva que o enunciador faz da historicidade de seu(s) encontro(s) com a(s) língua(s) que o habitam ${ }^{6}$.

A hipótese de trabalho básica é a seguinte. Assim como no escopo do cognitivismo realizaram-se estudos monográficos de acompanhamento do bilingüismo - a fim de

${ }^{3}$ Principalmente a proposta por M Pêcheux e equipe, com diversos desenvolvimentos, como os de J. Authier, na França, e E. Orlandi, no Brasil. Do campo de produção anglo-saxão, ainda que com diferenças conceituais, pelo fato de operar com a noção de interdiscursividade, pode-se mencionar o trabalho de $\mathrm{N}$. Fairclough.

4 Entendido como lugar de enunciação no jogo contraditório de relações de força e sentidos na sociedade.

${ }^{5}$ Fatores que, concomitantemente, condicionam o exercício de capacidades cognitivas.

${ }^{6}$ No trabalho publicado em 1998(b) apresento ilustrações do tipo de perguntas utilizadas na proposta AREDA. 
transferir conclusões para o desenvolvimento de estratégias na pedagogia de línguas - a proposta AREDA pode contribuir para a compreensão da incidência de fatores não cognitivos. Eles são, muitas vezes, determinantes do sucesso ou insucesso no processo de enunciar em segunda língua. Procura-se, dessa maneira, trazer subsídios para a compreensão desse processo, válidos nos campos teórico e aplicado dos estudos da linguagem.

Um dos princípios teóricos fundamentais na proposta AREDA é o de que, na produção/compreensão em segunda língua, materialidade lingüística e processo discursivo operam interdependentemente ${ }^{7}$. A materialidade é da ordem do sistema da língua, que só acontece em processos discursivos. Estes, por sua vez, podem ser analisados em dois níveis: o intradiscursivo e o interdiscursivo (cf. M. Pêcheux, 1988). $\mathrm{O}$ primeiro, corresponde à dimensão linear, à formulação efetivamente produzida considerado-se a cadeia do dito, em sua relação com o formulado imediatamente antes $\mathrm{e}$ com o que se segue. Trata-se da construção do tecido do representável, no qual se mostram relações como as de semelhança e dessemelhança, se enunciam propriedades atribuídas a objetos, que se apresentam ou se supõem organizados em classes, localizados em um tempo e um espaço específicos. Trata-se do âmbito discursivo no qual os objetos se ligam, isto é, do registro imaginário do discurso (cf. J. C. Milner, 1983). O mesmo, por sua vez, é interdependente do interdiscurso, que remete à dimensão vertical do dizer, à complexa rede de formaç̃̃es discursivas (cf. E. Orlandi, 1983) em que toda produção verbal está inserida. Entendo as formações discursivas como condensações de regularidades enunciativas no processo - constitutivamente heterogêneo e contraditório - da produção de sentidos no e pelo discurso, em diferentes domínios de saber. Focalizando a relação subjetividade-formação discursiva, N. Leite (1994:128) observa: "o conceito de formação discursiva nomeia a matriz simbólica na qual ganham sentido as representações imaginárias ligadas a uma dada posição na estrutura".

Para abordar e compreender essa dimensão não linear do discurso, opera-se com a noção de 'pré-construído' (cf. P. Henry, 1992, 1 ed. 1977), que é o sempre já aí, histórico-social, que fornece a matéria-prima, na qual o sujeito se constitui, e que remete, simultaneamente, a uma construção anterior, a partir da qual se produz o sentido 'construído' pelo enunciado. Tendo em vista o tema do singular na linguagem, foco deste volume, considero oportuno fazer uma observação relativa à conceituação de préconstruído. Nos textos da chamada primeira época da Análise do Discurso ${ }^{8}$, o préconstruído era qualificado como 'exterior'. Visava-se, assim, salientar a posição não imanentista nos estudos da linguagem. Nos desenvolvimentos posteriores da teoria, isto foi sendo caracterizado com maior precisão. Exterior e interior são instâncias que, em se tratando de linguagem, podem ser distinguidas, mas nem sempre separáveis. Na proposta AREDA, filiada às concepções não inatistas de aquisição, entende-se que o ser humano vem ao mundo sem a linguagem e ele recebe do exterior o significante, que é, a um só tempo, matéria-prima e instrumento da constituição do inconsciente do sujeito. $\mathrm{E}$ ao dizer 'sujeito' não se trata da mera articulação da entidade individual biológica do

${ }^{7}$ Princípio que é válido para a produção/compreensão verbal em geral, mas que, na proposta AREDA, aplica-se especificamente à enunciação em segunda língua, que é focalizada na pesquisa.

${ }^{8}$ Ver M. Pêcheux, 1990c. 
falante com os seus papéis no ambiente (tal como acontecia na Psicologia Social), mas de posição enunciativa, considerando-se as dimensões simbólica e significante.

A segunda noção crucial para a análise interdiscursiva é a de discurso transverso (cf. M. Pêcheux, 1988, l' ed. 1975). Este é composto pela existência de possibilidades de substituição entre 'diferentes' palavras, expressões, proposições com 'o mesmo sentido' e cuja análise diz respeito ao estabelecimento de posições subjetivas, afetadas por condicionamentos sócio-históricos e inconscientes. Há substituições simétricas e orientadas. As primeiras correspondem à simples relação de equivalência dentro de enunciados (por exemplo, aqueles construídos com verbos copulativos). O segundo tipo acontece quando a relação entre os substituíveis não resulta de uma relação simetricamente equivalente do ponto de vista sintático-semântico, como no caso das formulações cujo efeito discursivo é explicativo. O funcionamento do discurso transverso remete a ordens como as da metonímia, da relação da causa com o efeito, do sintoma com o que ele aponta (Pêcheux, 1988:166).

A seguir, referirei duas ilustrações de análises já realizadas no quadro da pesquisa AREDA, para depois de mostrar seu lugar em relação ao cognitivismo, examinando pressupostos teóricos e históricos das abordagens, pontualizar a concepção de singular trabalhada na proposta AREDA c a contribuição que pode resultar deste programa de investigação.

Em um dos estudos de caso realizados, o da enunciadora 'Joana', falante nativa de português, cuja segunda língua é o francês, em um depoimento sobre "choques culturais", ela disse: "mas eu enfrentei a mulher com o mesmo tipo de tom de voz, em primeiro lugar, e segundo, com a mesma rispidez, que eu já chamaria de falta de educação, em todo caso não era, ali não era, e devolvi na mesma, na mesma moeda." $\mathrm{Na}$ análise, focalizando o funcionamento discursivo da relativa "que eu já chamaria de falta de educação", e operando com a noção de discurso transverso, que supõe uma virtual seqüência vertical de outros sentidos possíveis, observamos que a enunciadora constrói uma posição que pode ser expressa assim: constatei "rispidez" que indica "falta de educação", na qual os termos entre aspas são da ordem dos substituíveis, próprios do discurso transverso. A enunciadora constrói, no discurso, a posição [rispidez = falta de educação], com a qual se identifica; mas, no mesmo depoimento, produz a incisa "em todo caso não era, ali, não era". Essa incisa funciona, no discurso, não somente como uma forma de desnível sintático, mas sobretudo como uma ruptura enunciativa na cadeia que, da perspectiva da análise do discurso, é relevante para abordar as posições discursivas. A incisa marca a materialização de um movimento contraditório do sujeito em relação à construção inicial [rispidez=falta de educação].

Em um outro estudo de caso efetuado com o enunciador 'César', falante nativo de espanhol, cuja segunda língua é o alemão, constatamos uma ressonância discursiva em torno do item lexical 'logicidade'. Ele diz: "El alemán me resultó fácil y lógico. Eso! Muy lógico". A representação de 'logicidade', no intradiscurso, é regras claras e ordem. Mas, posteriormente, 'César' diz: “... y en muchos sentidos yo sentía esa falta de espacio, esa logicidad imperiosa, aparente, en las definiciones y prioridades, que ya

${ }^{9}$ As transcrições no projeto AREDA reproduzem o mais fielmente possível aquilo que é efetivamente produzido pelo enunciador, uma vez que tudo, repetições, palavras incompletas, etc., interessa para a análise das ressonâncias discursivas

112 
estaban colocadas, en cosas que se habian intentado sucesivamente y entonces le quedaba a uno... aceptar uno o dos caminos digamos (...). Para mí esa logicidad se tornó terrible. Me daba una sensación así medio de tragedia griega." Nesta outra posição, o sujeito está em contradição com a identificação anterior com a logicidade, representada como "liberdade", "maravilha" e "alívio", e se desidentifica dela. As relativas em "definiciones y prioridades que ya estaban colocadas" e "cosas que se habian intentado sucesivamente y entonces le quedaba a uno aceptar uno o dos caminos" ressoam para a construção de um outro sentido para 'logicidade', construído também pela ressonância das formulações "falta de espaço", "terrível" e da comparação com a tragédia grega.

Antes de expor conclusões em relação a esses exemplos, discutirei como a construção relativa é concebida em abordagens que excluem a consideração do singular nos estudos da linguagem.

Como foi antecipado na Introdução, considero fundamental levar em conta, nos estudos da linguagem, perspectivas históricas e filiações teóricas. Assim, tratarei das relativas inserindo a questão em uma discussão mais ampla sobre paradigmas teóricos e sua construção discursiva. Observarei a concepção do universal e do singular no momento da denominada Gramática Geral do século XVII, examinando leituras contemporâneas do fenômeno.

\section{O UNIVERSAL COMO ESSENCIAL, O SINGULAR COMO CONTINGENTE NA GRAMÁTICA GERAL: SIGNIFICAÇÕES CONTEMPORÂNEAS}

As conseqüências teórico-metodológicas do reforço dado, na década de sessenta, à linha conceitual que exclui o singular, a historicidade do sujeito e do sentido nos estudos da linguagem, continuam até hoje. Tanto em livros e artigos daquela década como em textos muito recentes ${ }^{10}$ utiliza-se, na construção do referido reforço, uma leitura da significação da Gramática Geral. Principalmente em sua Lingüística Cartesiana $^{l l}$ (1966, ed. Bras. 1972), Noam Chomsky trouxe à tona a discussão sobre a Gramática Geral e Razoada (GGR) de Port-Royal (1660, ed. Brasileira de 1992) ${ }^{12}$, constituindo-a em antecedente crucial da Gramática Gerativa e do cognitivismo inatista que a sustenta. Assim também o fizeram outros expoentes do gerativismo como, por exemplo, R. Lakoff. A autora questiona que a GGR esteja na origem e insiste na importância, negligenciada por Chomsky, de estudiosos da Renascença, como Sanctius, gramático espanhol da Universidade de Salamanca. Essa observação se reveste de importância, porque leva a questionar o atributo de 'cartesiana', tão difundido na época. Mas, apesar das críticas, R. Lakoff (1969: 346) assume: "Nem sempre é claro que as

${ }^{10}$ Cf. N. Chomsky, 1997.

${ }^{11}$ E nos capítulos 1 e 3 de Language and Mind, New York, 1968.

12 A GGR foi reeditada, na França, em 1664, 1679, 1709, 1754 e que teve sua primeira edição em inglês em 1753. Contemporanemente, podemos mencionar a edição, em 1966, de Herbert H. Brekle (StuttgartBad Cannstatt: Friedrich Fomann Verlag) e a francesa de 1969, com prólogo de M. Foucault. Como indicado, há edição brasileira recente (1992). 
razões que levam os lingüistas do século $\mathrm{XX}$ a fazer uma afirmação, ou a dar um certo exemplo, sejam as mesmas que influenciaram sua contrapartida do século XVII. (...) Mas isso não significa que Lancelot e Arnauld não foram, em algum sentido, gramáticos gerativistas. Ao contrário, eu afirmaria definitivamente que eles o foram."13

O atributo 'cartesiana' pareceu inadequado a mais de um estudioso. Além do questionamento sobre a referência insignificante feita por Chomsky à importância de Sanctius, foi apontada a influência da filosofia de Locke, sobretudo nos lógicos de PortRoyal (cf. H. Aarsleff, 1970). Posteriormente, o próprio Chomsky (1997) reformulou superficialmente suas posições, incorporando observações feitas pelos críticos. Contudo, ele não aceitou nunca os questionamentos de base, nem respondeu efetivamente às perguntas sobre ausências significativas em seu recorte do período, como, por exemplo, a de Condillac. Aarsleff apresenta evidências sobre as ligações de Du Marsais e Condillac com grupos que seguiam as posições de Locke, contrário ao inatismo. Segundo o crítico, a concepcão de inatismo propugnada por Chomsky difere em grande medida do sentido de disposição e propensão em Descartes (1647, 1987:442) (cf. Aarsleff, op.cit.: 582).

O que possibilita a leitura e o aproveitamento gerativista é o fato de que, na Gramática de Port-Royal, "é permitido discernir retrospectivamente a ausência perfeitamente determinada de uma teoria da enunciação" (Pêcheux, 1988). Poderá parecer extemporâneo perguntar-se por 'enunciação' referindo-se a uma obra do século XVII. Mas se pensarmos no Tratado Teológico-Político de Spinoza, de 1670, no qual, sobretudo nos capítulos II, VII e VIII, o filósofo fala (nos termos de seu tempo, obviamente) sobre a importância de se perguntar sobre as condições de produção dos textos na hora de estudá-los, sobre a produção metafórica dos sentidos, sobre a não coincidência de palavra e coisa e no qual, é até mesmo possível constatar um exercício espontâneo dos princípios de contradição, pode-se concluir que refletir sobre antecedentes como esses contribuirá, sem dúvida, para a compreensão do fenômeno da enunciação, em perspectiva ${ }^{14}$.

Mas, voltando a Port-Royal, evidentemente, a análise do pensamento que se pratica na GGR é a análise lógica, ao se considerar que é a que permite decompô-lo, respeitando a unidade a ele atribuída. A principal forma de pensamento (embora não a única) é o juízo, e sua expressão linguíistica é a proposição. Nela distinguem-se um sujeito (entendido aqui como aquilo de que se afirma alguma coisa) e um atributo (aquilo que ê afirmado dele). Cada um desses termos define-se em relação ao outro porque, nessa perspectiva, o sujeito é sujeito somente em relação a uma atribuição possível - (cf. Ducrot, 1972). O sujeito e o atributo podem ser simples (como em "a casa é grande") ou complexos (como em "um hábil magistrado é um homem útil à república") $)^{15}$.

Como se pode ver, as construções relativas merecem um destaque especial no estudo do pensamento lógico de Port-Royal. Entende-se que, em geral, as construções

${ }^{13}$ A tradução é minha. Esse será o caso sempre que, nas Referências Bibliográficas, o título da obra conste em inglês ou francês.

${ }^{14}$ Cf. Spinoza, Tratado Teológico-Político, in Obras Escogidas, Buenos Aires, El Ateneo, 1953, pp. 29-336.Cf., também, M. Pêcheux, 1988 e 1990b.

${ }^{15}$ GGR, 1992:64. 
de um nome, tendo como aposto um nome, um adjetivo ou um particípio, encerram o relativo no sentido (o clássico exemplo dado na GGR (1992:64) é: "Deus invisível criou o mundo visível", "Deus, que é invisível, criou o mundo, que é visível"). Na Lógica de Port-Royal, obra gêmea da Gramática Geral e Razoada, esclarece-se o fundamento da distinção entre relativas explicativas e determinativas. A distinção baseia-se em uma análise da compreensão e da extensão das idéias universais. A compreensão de uma idéia é o conjunto de atributos essenciais que a definem, juntamente com tudo aquilo que pode ser deduzido deles; sua extensão é o conjunto de objetos que denota. No caso da relativa explicativa, a idéia expressa já está contida na idéia da principal ou é a idéia de alguma característica acidental da idéia expressa pela palavra principal. A relativa determinativa acontece quando a extensão da idéia expressa pela subordinada é menor do que a extensão da idéia expressa pela palavra principal (como no exemplo "Os homens que são piedosos são caritativos", no qual não se diz que todos os homens são piedosos) ${ }^{16}$. A relativa, neste caso, determinativa é chamada também de restritiva. $\mathrm{E}$ sobre este tema específico M. Pêcheux (1988: 44) faz a seguinte observação: "A relação determinativa, pelo jogo de relação entre compreensão e extensão, diz respeito exclusivamente à ordem do ser, ao mundo das essências, fora de toda adjunção do pensamento: estamos no nível em que o ser se designa a si mesmo. A relação explicativa, ao contrário, intervém como uma incidência do pensamento sobre a ordem das essências." Assim, serão "incidentes", termo usado por Arnauld e Lancelot, somente as relativas explicativas, como "que é invisível" e "que é visível", no primeiro exemplo tratado neste parágrafo.

Para os gerativistas-cognitivistas parece exato considerar sua teoria essencialmente uma versão moderna e mais explícita da teoria de Port-Royal (cf. Chomsky, 1972:50). Eles interpretam que há, na GGR, um nível lógico universal subjacente, e crêem que sua forma subjacente não precisa ser igual à que aparece na superfície, ou seja, pode ser retirada da construção mais profunda" (cf. R. Lakoff, op.cit: 346). No meu entender, é possível estabelecer algumas semelhanças entre o pensamento lógico da Gramática Geral e os estudos da linguagem da corrente formalista-logicista e a teoria cognitivista em aquisição do século XX. Porém, penso também, inspirada em observações como as de M. Foucault (1969), que a Gramática Geral não é uma quase Lingüística nem a Lingüística moderna é uma forma mais positiva dada à velha idéia de Gramática Geral. Trata-se de duas configurações epistemológicas diferentes, cujo objeto não se recorta da mesma forma, cujos conceitos não possuem, em absoluto, o mesmo lugar nem a mesma função. A Gramática Geral e Razoada de Port-Royal constitui para a análise da linguagem um novo espaço epistemológico, um novo modo de aparição dos objetos gramaticais, um novo estatuto para sua análise, uma nova maneira de formar os conceitos (ibidem). E isso se deve, principalmente, ao fato de que ela permite superar o dilema entre a gramática puramente filosófica, como as medievais, dedicadas à reflexão geral sobre $o$ ato de significar, e a gramática puramente empírica, como a de Vaugelas $^{17}$, dedicada aos 'bons usos'. Ora, Port-Royal se posicionou contra os

\footnotetext{
${ }^{16}$ Cf. Lógica de Port-Royal, ed. em inglês de 1964: 59-60.

${ }^{17}$ Remarques sur la langue française, de 1647.
} 
defensores do 'bel usage'. A GGR procura dar uma explicação dos usos particulares a partir de regras gerais deduzidas ${ }^{18}$.

A Gramática Geral e Razoada resulta de um contexto que não deve ser negligenciado. Como se sabe, o mosteiro de Port-Royal foi um centro cultural, pivô de reformas pedagógicas e espaço de disputas teológico-políticas complexas. Foi porta-voz do jansenismo, doutrina dos seguidores de Corneille Jansen, que propugnava que o batismo sustenta o homem até o uso da razão; a partir daí, é trabalho da educação fazer com que continue nesse estado (de Graça). O importante conflito com os jesuítas teve consequiências em diversos domínios socioculturais, mas não nos deteremos nele por não fazer parte dos objetivos deste trabalho ${ }^{19}$. Interessa aqui, sim, lembrar que PortRoyal está associada a um projeto de renovação no ensino de línguas ${ }^{20}$, para refletirmos sobre as implicações disso.

Os manuais utilizados até aquele momento enunciavam as regras da gramática, que faziam parte da exercitação, na língua alvo. A reforma consistiu em distinguir dois planos: o da língua materna (ou mais familiar para o aluno) e o da língua a ser aprendida. $\mathrm{O}$ projeto de Port-Royal teve conseqüências também para a prática da língua materna, pois dentro de 'língua a ser aprendida', se consideravam também os princípios gramaticais, no caso da língua em estudo ser a própria. E na interpretação dada pelos cognitivistas contemporâneos ficou de fora a consideração de elementos fundamentais para uma compreensão mais aprofundada. Além da questão dos debates teológicopolíticos já mencionados, há um outro fator, a meu ver, não desprovido de relevância: a inovação de Port-Royal teve efeitos culturais consideráveis no que diz respeito a uma consciência mais aguda das nacionalidades linguísticas, do vocabulário e da sintaxe próprias de cada língua. Ela marcou, ao menos como proposta, o fim do privilégio da gramática latina.

$\mathrm{Na}$ leitura realizada pela corrente gerativista contemporânea das propostas de PortRoyal, no que diz respeito às construções relativas determinativas e explicativas, o singular é entendido como contingente, em relação a um universal, concebido como essencial. Vimos que Port-Royal é um fenômeno muito complexo para que sua significação seja restrita a mero antecedente do chomskismo. O que nos interessa salientar aqui é que a construção discursiva feita pelo cognitivismo visou a construir um paradigma que excluísse a singularidade enunciativa do estudo do sentido, focalizando a questão de o sentido estar reduzido à lógica da sentença.

${ }^{18}$ Cf. O. Ducrot, 1972.

${ }^{19}$ Para quem se interessar em aprofundar a compreensão das polêmicas entre jansenistas e jesuítas, remetemos o leitor aos trabalhos de L. Goldman, Le Dieu caché, Gallimard, 1959; C. Haroche, Faire dire, vouloir dire, Lille, PUL, 1983 e D. Maingueneau, Sémantique de la polémique, Lausanne, L'Age d'Homme, 1983 e, nos quais, por sua vez, consta abundante bibliografia complementar sobre o tema.

${ }^{20}$ No Prefácio à edição brasileira da Gramática de Port-Royal há uma descrição detalhada do funcionamento das Escolas de Línguas (cf. B. Bassetto e H. Murachco, 1992). 


\section{ENUNCIADO, ENUNCIAÇÃO E SINGULARIDADE DISCURSIVA NA "AQUISIÇÃO" DE LÍNGUAS}

A seguir, sintetizarei algumas conclusões (parciais) em relação às perguntas formuladas no início deste texto. Elas motivaram tanto a elaboração da proposta AREDA como a crítica da leitura da Gramática Geral, feita pelo cognitivismo gerativista. Repensarmos, em perspectiva, essa postura teórica, também diz respeito às referidas questões. Ela continua a retornar como embasamento de abordagens que insistem em estudar o processo de enunciar em L2 como resultante de 'inputs' e 'outputs' informacionais ${ }^{21}$.

Convém, também, fazer algumas especificações sobre o alcance da expressão 'aquisição de segunda língua'. Ela acabou confirmada pelo uso e, institucionalmente, é utilizada para estabelecer distinções disciplinares, departamentais, editoriais, etc. Entretanto, seu uso parece-me adequado, desde que fique esclarecido que a produção lingüístico-discursiva em segunda(s) língua(s) não resulta de algo meramente adquirido, incorporado, por um sujeito separado da língua e da discursividade na qual se realiza, como se o processo fosse de estocagem de palavras e de aplicação de regras de combinação. Sujeito, língua e discursividade estão imbricados substancialmente. 0 sujeito recebe, sim, do exterior, a linguagem. Mas, no processo de enunciar e compreender, exterior e interior são instâncias que, embora distinguíveis, nem sempre são separáveis. Concebo o processo de enunciar significativamente em L2 como um processo estreitamente ligado a inscrições identificatórias na discursividade da língua alvo, decorrente de identificações e desidentificações vividas em relação à(s) segunda(s) e primeira língua, sendo as mobilizações, em relação a esta última, cruciais ${ }^{22}$. A proposta AREDA se dispõe como um caminho para estudar o processo nessa perspectiva.

A preocupação com o fato de o aprendiz, no caso das línguas segundas e estrangeiras, não possuir a materialidade de uma dada língua, parece reforçar a postura que privilegia a dimensão específica do saber lingüístico, no que diz respeito à lógica do enunciado, desconsiderando-se, ou considerando-se de modo precário ou banal, sua relação com a enunciação. Não é raro que, tanto em estudos de bilingüismo em imersão como em propostas didáticas na área de "aquisição" de línguas estrangeiras, a enunciação fique reduzida a interações em contextos des-historicizados, ou que não possibilitem que a singularidade enunciativa venha à tona. $\mathrm{O}$ implícito tem sido muitas vezes que a língua preexiste ao discurso, que haveria estruturas e léxico a serem adquiridos antes para depois serem usados. Na verdade, a língua não preexiste ao discurso. As duas dimensões são interdependentes. Há sim, como diria Pêcheux, condições materiais de base, mas elas são linguísticas $e$ históricas ${ }^{23}$. Do contrário, não haverá efeitos de sentido produzidos pela linguagem verbal.

${ }^{21}$ Como faz, por exemplo, Krashen.

22 Discuti o funcionamento dos processos identificatórios na enunciação em L2 em "Identidade e Segundas Linguas: As Identificações no Discurso", 1998a.

${ }^{23}$ Um exame muito interessante sobre fronteiras entre Ciências da Linguagem, História e Ciências Sociais, encontra-se em Corrêa, 1999. 
$\mathrm{Na}$ aprendizagem de uma língua estrangeira há um momento no qual aparece com maior evidência a operação de nomeação. Mas ela é sempre, simultaneamente, uma predicação, um modo de situar aquilo que está sendo nomeado numa rede de valores e sentidos que, da perspectiva da Análise de Discurso, é entendida como rede de formações discursivas. Quando se toma a palavra, toma-se uma posição enunciativa, que dirá respeito a processos identificatórios, a relações de poder decorrentes de filiações sócio-históricas e redes de memória constitutivas do sujeito. Constitutivas porque já antes de falar a criança está imersa num mundo de dizeres, posições assumidas ou denegadas - , nas quais sempre há interpretações feitas sobre o pequeno ser e seu sentir, sobre o mundo a sua volta, sobre expectativas em relação a ele e assim por diante. É o que em um trabalho anterior ${ }^{24}$ chamei de 'formações discursivas fundadoras', querendo significar aquilo que está inscrito no sujeito juntamente em/com as palavras da primeira língua. Isso será o que o encontro com segunda(s) língua(s) questionará, mobilizará, perturbará.

A aprendizagem de segunda(s) língua(s) solicita os fundamentos da estruturação psíquica do sujeito e o que é instrumento e matéria dessa estruturação: a língua materna ${ }^{25}$. A mesma entendida não necessariamente como língua nacional, mas como aquela que teceu o inconsciente, aquela que, para cada um, constitui a língua da estrutura simbólica fundamental ${ }^{26}$. Mas essa estrutura - por ser singular - não deixa de estar inscrita numa rede de memórias discursivas, nas quais posições particulares resultam de relações contraditórias de poder e sentido, num determinado contexto sócio-histórico ${ }^{27}$. O encontro com segunda(s) língua(s) materializará uma contradição específica, representada por "ganhos" e "perdas": relativização da língua materna e suas formações discursivas fundadoras, "ganhos" de liberdade, vivências do 'novo' em contradição com sensações de perda de 'identidade'. Na superação desse processo contraditório serão cruciais as identificações do sujeito. No caso específico da enunciação em L2, a proposta AREDA analisa a representação discursiva de identificações do sujeito condicionantes de sua produção em segunda língua. Assim, no exemplo referido com a enunciadora Joana, o 'objeto de discurso' 'educação/falta de educação' foi de grande incidência no modo de acontecimento de sua enunciação em francês, como a análise de muitos outros depoimentos confirmou. No outro exemplo apresentado, trata-se das representações de 'logicidade'. Como se vê, na enunciação em segundas línguas, trata-se de muito mais do que de uma questão de formas lingüísticas e funções. Trata-se do sujeito e sua singularidade contraditória posta em questão pelo encontro com segundas línguas.

${ }^{24}$ Cf. revista DELTA, 13, 1, São Paulo, 1997, pp. 63-81.

${ }^{25}$ Cf. C. Revuz, 1998. Sobre a aquisição da língua materna, ver De Lemos, 1992 e Pereira de Castro, 1998.

${ }^{26}$ Cf. Melman, 1992.

${ }^{27}$ Cf. Calligaris, 1992 e 1997 (Agradeço a Nina Leite a cessão desta última referência bíbliográfica). Ver, também, Pêcheux, 1990a. 


\section{REFERÊNCIAS BIBLIOGRÁFICAS}

AARSLEFF, H. (1970) "The History of Linguistics and Professor Chomsky". Language 46, 1, pp. 570-585.

ARNAULD E LANCELOT, (1969, led. 1660) Grammaire générale et raisonnée, Paris, 1969. Edição brasileira: Gramática de Port-Royal ou Gramática Geral e Razoada, São Paulo, Martins Fontes, 1992.

BASSETTO, B. E MURACHCO, H. (1992) "Prefácio à Edição Brasileira", in Gramática de Port-Royal ou Gramática Geral e Razoada, São Paulo; Martins Fontes.

CALligaris, C. (1992) Hello Brasil! Notas de um Psicanalista Europeu Viajando ao Brasil. São Paulo: Escuta.

(1997) "Sociedade e Indivíduo", in Fleig, M. Psicanálise e Sintoma Social. São Leopoldo: UNISINOS, PP. 183-196.

CHOMSKY, N. (1972) Lingüística Cartesiana. Trad. Francisco M. Guimarães. Petrópolis: Vozes e São Paulo: Editora da USP.

. (1997) "Conhecimento da História e Construção Teórica na Lingüística Moderna". D.E.L.T.A Vol. 13 $\mathrm{N}^{\mathrm{B}}$ Especial, São Paulo: EDUC, pp. 129-152.

CORRÊA, M G. (1999) "Lingüística, Lingüística Aplicada e Análise do Discurso em um Estudo na Fronteira com a História e as Ciências Sociais". Anais do III Simpósio em Filosofia e Ciência-Educação, UNESP, Marilia, no prelo.

DE LEMOS, C. T. G. (1992) "Los procesos metafóricos y metonímicos como mecanismos de cambio". Substratum 1, pp. 121-135.

DUCROT, O (1972) "Grammaires générales" in O Ducrot e T. Todorov, Dictionnaire encyclopédique des sciences du langage. Paris: Éditions du Seuil, pp. 15-19.

FOUCAULT, M. (1969) "Introduction" in Arnauld e Lancelot, Grammaire génerale et raisonnée. Paris: Republications Paulet, pp. III- XXVIII.

GADET, F E HAK, T (Orgs) (1990) Por uma Análise Automática do Discurso. Uma Introdução à Obra de Michel Pêcheux. Campinas: Editora da UNICAMP.

GOLDMAN, L. (1959) Le Dieu caché, Paris: Gallimard.

HAROCHE, C. (1983) Faire dire, vouloir dire, Lille, PUL, 1983.

HENRY, P. (1992) A Ferramenta Imperfeita. Campinas: Ed. da Unicamp.

LAKOFF, R. (1969) "Reviews - Grammaire générale et raisonnée, Edited by Herbert H. Brekle". Language Vol. 45, 2, pp.343-367.

LEITE, N. (1994) Psicanálise e Análise do Discurso. O Acontecimento na Estrutura. Rio de Janeiro: Campo Matêmico.

MAINGUENEAU, D. (1983) Sémantique de la polémique, Lausanne, L'Age d'Homme.

MELMAN, C. (1992) Imigrantes: Incidências Subjetivas das Mudanças de Lingua e País. São Paulo: Escuta.

MILNER, J.C. (1983) Les noms indistincts. Paris: Éditions du Seuil.

ORLANDI, E. (1983) A Linguagem e seu Funcionamento, Campinas, Pontes.

PÊCHEUX (1988) Semântica e Discurso. Uma Crítica à Afirmação do Óbvio. Trad. E. Orlandi, L. Chacon, M. Corrêa e S. Serrani. Campinas: Editora da Unicamp. 
. (1990a) Discurso: Estrutura ou Acontecimento. Trad. E. Orlandi. Campinas: Pontes.

(1990b) L'Inquiétude du discours. Paris: Éditions des Cendres.

(1990c) "Análise de Discurso: Três Épocas". Trad. Jonas de A. Romualdo. in, F. Gadet e T. Hak

(Orgs.) Introdução à Análise Automática do Discurso, Campinas, Ed. da Unicamp, pp. 311-318.

PEREIRA DE CASTRO, F. (1998) "Língua Materna: Palavra e Silêncio na Aquisição de Linguagem". Trabalho apresentado na Mesa Redonda A Aquisição da Linguagem e a Linguagem Perdida, IEL, UNICAMP.

REVUZ, C. (1998) "A Língua Estrangeira entre o Desejo de um Outro Lugar e o Risco do Exílio" Trad. Silvana Serrani, in I. Signorini (Org.) Lingua(gem) e Identidade. Campinas: Mercado de Letras, pp. 213-230.

SERRANI-INFANTE, Silvana (1997) "Formações Discursivas e Processos Identificatórios na Aquisição de Línguas", DELTA 13, 1. São Paulo: EDUC, pp. 63-81. . (1998a) "Identidade e Segundas Línguas: as Identificações no Discurso" in I. Signorini (Org.) Língua(gem) e Identidade. Campinas: Mercado de Letras, pp.231- 264. . (1998b) "Abordagem Transdisciplinar da Enunciação em Segunda Língua: a Proposta AREDA" in M. Cavalcanti e I. Signorini (Orgs.), Lingüística Aplicada e Transdisciplinaridade. Campinas: Mercado de Letras, pp. 143-167. 